\title{
Skrubbsår med uvanlig forløp
}

\author{
Traumatiske sår i huden er meget vanlig og omfatter alt fra alvorlige \\ brannskader til overflatiske skrubbsår. Normalt vil sår heles i løpet \\ av to til tre uker, men det er flere faktorer som kan forlenge helings- \\ fasen. Her beskrives to sykehistorier som viser sår med kompliserende, \\ uvanlige forløp.
}

Se kommentar side 307 og kunnskapsprøve på www.tidsskriftet.no/quiz

Pasient 1. En 46 år gammel kvinne hadde falt på sykkel og pådratt seg kutt på haken. Det ble suturert ved legevakten og grodde fint. Sykkelveltet medførte også overflatiske sår på håndryggene og $i$ venstre håndflate og et lineært sår på venstre underarm. Disse tilhelte ikke normalt.

Det ble påvist oppvekst av gule stafylokokker. Pasienten fikk behandling med klaritromycin (Klacid) $i$ to omganger, med noe bedring initialt.

Til lokalbehandling ble hun anbefalt klorheksidinliniment og Brulidine-krem, som hun brukte opptil tre ganger daglig med Meloline-kompresser over.

På grunn av manglende bedring ble kvinnen fem uker etter sykkelveltet undersøkt ved Hudpoliklinikken. Hun var i god allmenntilstand.

Det var et relativt skarpt avgrenset område, $10 \times 13 \mathrm{~cm}$, dorsalt på venstre underarm med papulovesikuløse eksematøse erosive elementer. I tillegg var det ulcerasjoner dorsalt på de tre midtre metakarpofalangealleddene (MCP-leddene) på venstre hånd og palmart på høyre hånds femte MCP-ledd. Sårkantene var eleverte og uttalt erytematøse (fig 1-3). På huden rundt ulcerasjonene var det papulovesikuløse eksematøse lesjoner.

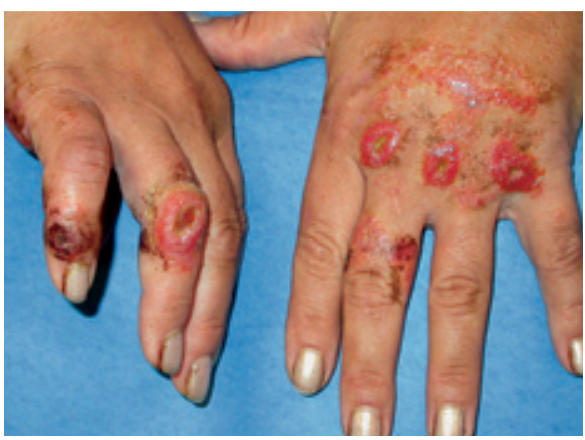

Figur 1 Pasient 1. Sentral nekrose, eleverte sårkanter. Pasienten har gitt samtykke til at bildene blir publisert. Alle foto Hudavdelingen, Rikshospitalet
Pasientens ulcerasjoner tilhelet ikke til tross for god etterlevelse av anbefalt behandling. Ved ulcerasjoner som ikke tilheler, bør man differensialdiagnostisk først og fremst vurdere pågående infeksjon. Andre forklaringer på manglende tilheling kan være karskader, immunologiske tilstander, hudkreft, allergi mot lokalbehandlingen og artefakter.

For å komme frem til den rette diagnosen er det viktig med en grundig klinisk undersøkelse og adekvat bruk av supplerende utredning. Ved infeksjon i et sår vil bakteriologisk undersøkelse verifisere diagnosen. Karskader med venøs eller arteriell insuffisiens eller nedsatt mikrosirkulasjon, som ved diabetes mellitus, er ofte årsaken til manglende tilheling av sår på underekstremitetene. Sår her krever derfor ofte karfysiologisk utredning. Immunologisk betingede sår, først og fremst vaskulitt og pyoderma gangrenosum, er sjeldent, men kan oppstå i normal hud eller i allerede eksisterende sår. Biopsi med immunfluorescensundersøkelse kan styrke diagnosen, men er ikke alltid diagnostisk. Ulcererende hudkreft har ofte et langtrukkent forløp. Diagnosen stilles ved biopsi. Uvanlige sår kan sjeldne ganger være artefakter og diagnosen er vanskelig å stille. Allergi mot lokalbehandling kan være årsaken til at sår ikke tilheler på vanlig måte eller øker i omfang. Ved kontakt-

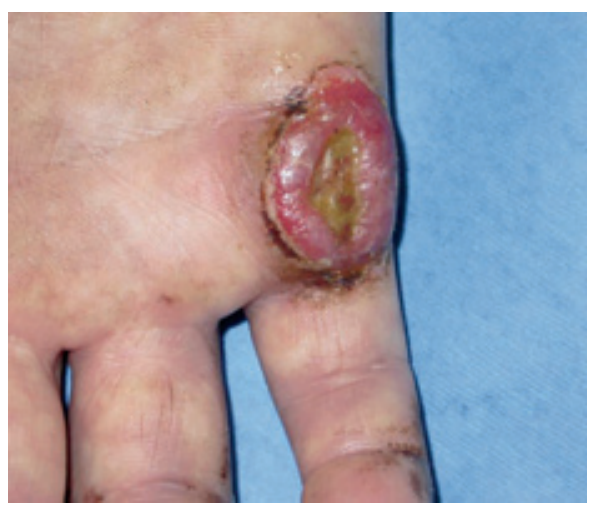

Figur 2 Pasient 1. Ulcerasjon volart 5. MPC-ledd på høyre hånd allergi vil det i relasjon til ulcerasjonen være et kløende eksematøst utslett.

Et akutt eksem bærer preg av hissig erytem, papulovesikler, væsking og kløe. Allergisk og irritativt kontakteksem er hyppige årsaker til akutt eksem. Atopisk eksem kan ha akutte eksaserbasjoner, spesielt ved superinfeksjon. Andre differensialdiagnoser er fototoksiske eller fotoallergiske reaksjoner. Angioødem med hovne øyelokk og tidlig herpes zoster kan likne eksem. Erysipelas er også erytematøs, akutt og smertefull, men pasienten er syk med feber og forhøyede infeksjonsvariabler.

I tillegg til ulcerasjonene hadde denne pasienten et hissig eksem som gjorde at man ved Hudpoliklinikken relativt tidlig mistenkte kontaktallergisk dermatitt som den mest sannsynlige diagnose. Den tentative diagnosen ble styrket ved negative infeksjonsprøver og pasientens gode allmenntilstand. Dibrompropamidin, innholdsstoffet i Brulidine-krem, ble mistenkt som utløsende agens. Preparatet var brukt hyppig over lengre tid, det hadde vært lite annen lokalbehandling.

Det viktigste ledd $i$ behandlingen av allergisk kontakteksem er å eliminere allergenet. For å få hurtig bedring vil man ofte behandle med lokale eller systemiske kortikosteroider.

Pasienten ble bedt om å seponere dibrompropamidin. Siden hun hadde uttalt og utbredt utslett valgte man å behandle med prednisolontabletter i ti dager. Til sårene fikk hun forskrevet en antiseptisk krem inneholdende hydrogenperoksid (Microcid-krem).

Ved kontroll ved Hudpoliklinikken etter to måneder hadde pasienten hovedsakelig arrdanning, men fremdeles lette eksematøse forandringer.

Hun var instruert i brukertest og hadde før

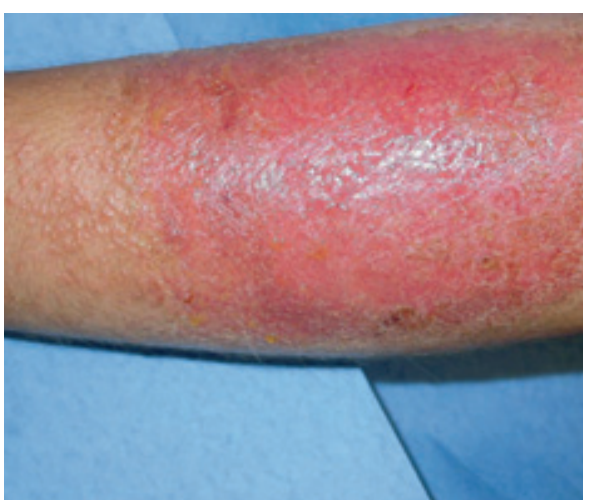

Figur 3 Pasient 1. Hissig erytem og væsking på venstre underarm 


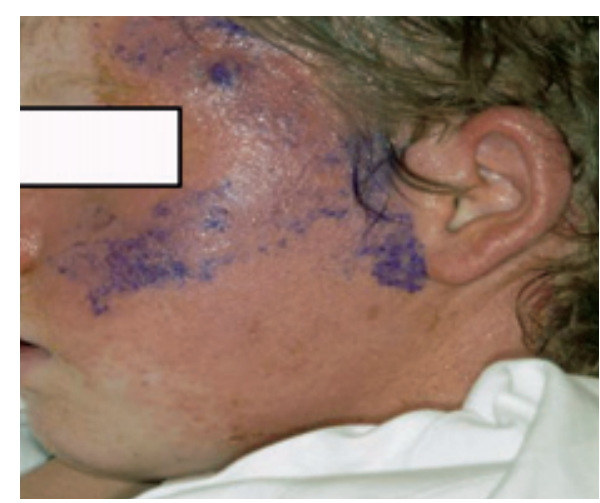

Figur 4 Pasient 2. Væskende eksem i venstre ansiktshalvdel. Pasientens pårørende har gitt samtykke til at bildene blir publisert

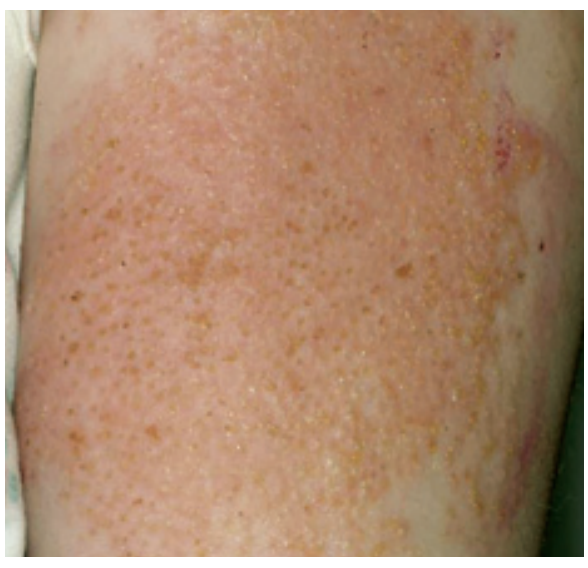

Figur 5 Pasient 2. Væskende dermatitt på overarm

avsluttende kontroll smurt Brulidine-krem på et område på innsiden av venstre underarm. Man avleste en sikker positiv reaksjon med papulovesikuløst utslett og lokal spredning.

\section{Andre kliniske erfaringer}

Pasient 2. En 15 år gammel gutt hadde utviklet en smertefull kvise i venstre tinning. Etter manipulering utviklet det seg skorper og rødhet. Allmennlegen tolket utslettet som impetigo, og pasienten fikk behandling med erytromycin peroralt og fucidin salvekompresser, deretter overgang til dikloksacillinkapsler. Utslettet forverret seg kraftig, og pasienten ble innlagt i Hudavdelingen som øyeblikkelig hjelp tre uker etter symptomstart.

Han var afebril, men slapp, sengeliggende og plaget med kløe. Han hadde et papulovesikuløst, væskende, erosivt og erytematøst område som omfattet store deler av venstre ansiktshalvdel. På venstre overarm var det en lesjon på $6 \mathrm{~cm}$ i diameter med tettstilte papulovesikler (fig 4, fig 5).

Tentativ diagnose var impetiginisert primær herpesinfeksjon. Dikloksacillin, som pasienten sto på ved innkomst, ble kontinuert og supplert med valaciklovir og antiseptisk lokalbehandling. Ved visitt fire dager etter innleggelsen var det ingen bedring $i$ utslettet. Blodprøvene var normale. Det var negativ virusdyrking i cellekultur fra sårsekret, og varicella zoster-antigenimmunfluorescens var negativ. Det kliniske bildet med uttalt væskende dermatitt, kløe, forholdsvis god allmenntilstand og lite utfall $i$ blodprøver - ga mistanke om kontaktallergisk eksem. Det ble utført en grundig anamnese med henblikk på lokalbehandling. Det viste seg at pasienten regelmessig gjennom hele sykdomsperioden hadde brukt Brulidine-krem. Brukertest på Brulidine-krem var sterkt positiv - med papulovesikler med spredning. Pasienten ble behandlet med kortisonkrem, med bedring av tilstanden.

Tabell 1 Vanlige allergener i topikale medikamenter (6)

$\begin{array}{ll}\text { Kategori } & \text { Eksempler } \\ \text { Vehikkel } & \text { Lanolin, cetylalkohol } \\ \text { Konserveringsmidler } & \text { Parabener, kloroacetamid, quarternium 15, Euxyl K 400'1 } \\ \text { Aktive ingredienser } & \begin{array}{l}\text { Antibiotika, quinoloner, lokal anestesi, antihistaminer, solfaktor, } \\ \text { kortikosteroider, NSAID-stoffer, eldre antimykotiske midler }\end{array} \\ \text { Parfymer } & \text { Mange }\end{array}$

${ }^{1}$ Miks av fenoksyetanol og metyldibromoglutaronitril

Tabell 2 Vanlige produkter til daglig bruk som kan gi kontaktallergi

\begin{tabular}{|c|c|}
\hline Produkt & Innholdsstoff som fører til kontaktallergi \\
\hline Kosmetikk & $\begin{array}{l}\text { Quaternium 15, paraben, formaldehyd, neomycin, parafenylenediamin, } \\
\text { lanolin, kathon CG, parfyme, perubalsam }\end{array}$ \\
\hline Neglelakk & Metakrylat \\
\hline Hårfarge & Parafenylenediamin, koboltklorid, nikkel \\
\hline Deodorant & Neomycin, parfyme, parabener \\
\hline Fuktighetskrem & Lanolin, quaternium 15, paraben, kathon CG, parfyme \\
\hline Såpe & Paraben, quaternium 15, formaldehyd, kathon CG, neomycin \\
\hline Solkrem & Solfaktorer og som fuktighetskrem \\
\hline
\end{tabular}

\section{Diskusjon}

Brulidine er en antiseptisk krem der det aktive stoffet er dibrompropamidin. Den brukes til behandling av lokale hudinfeksjoner (1) og kan kjøpes reseptfritt i tuber på $25 \mathrm{~g}$. Folkehelseinstituttets grossistbaserte legemiddelstatistikk viser at det i perioden 2004-06 ble solgt 140 455-146 223 tuber årlig.

I preparatomtalen nevnes som bivirkninger lokal irritasjon på applikasjonsstedet. Kontraindikasjon for bruk er kontaktallergi mot parahydroksybenzoatderivater og bromømfintlighet. I litteraturen er det flere tilfeller av kontaktallergi ved bruk av kremer som inneholder dibrompropamidin $(2,3)$. Siden kremen er reseptfri, vil man anta at en del pasienter selv vil konstatere allergi uten å oppsøke lege. Det er derfor sannsynlig at antall personer med kontaktdermatitt etter bruk av krem med dibrompropamidin er underrapportert.

Andre lokale antiseptiske midler som selges i Norge er klorheksidinpreparater, jodpreparater, cetylpyridin (Pyrisept), hydrogenperoksid (Microcid) og kaliumpermanganat. Disse preparatene tolereres stort sett bra, men alle har potensial til å skape kontaktdermatitt (4).

\section{Kontaktallergi}

Kontaktallergi er en T-cellemediert immunrespons, en type IV-reaksjon i epidermis og dermis (5). En lang rekke molekyler kan virke som allergener. Allergenet tas opp i epidermis av langerhansceller eller makrofager og presenteres for CD4- og CD8-positive Tceller i lymfeknutene. Dette fører til aktivering og oppregulering av T-cellene. Det tar fra fem til sju dager å produsere tilstrekkelig antall T-lymfocytter for å gi det kliniske bildet av kontakteksem. Når man er sensibilisert, behøves det minimal hudkontakt for å få en oppblussing av eksemet. Reaksjonen er størst etter 48-72 timer.

Det kliniske bildet er preget av papulovesikuløse eksematøse forandringer og kløe i det eksponerte området. Ved kontaktallergi i et område med ulcerasjon vil såret ofte ikke tilhele og i noen tilfeller øke i størrelse. På omkringliggende hud vil man kunne observere eksematøse forandringer.

I forbindelse med sår og utslett er det ikke uvanlig å se utvikling av allergi mot behandlingsprodukter og bandasjemateriell (tab 1) (6). Insidensen av kontaktallergi øker i takt med eksponeringen, stoffets konsentrasjon og hvor god hudens beskyttende evner er. Allergi mot topikale midler er vanligst hos pasienter med defekt hudbarriere, slik som kroniske sår og eksem. I behandlingsøyemed vil pasienten eksponeres for topikale midler over lengre tid, og man antar at dette er noe av forklaringen til den økte hyppigheten (7-10). Man kan imidlertid også se utvikling av kontaktallergi på frisk hud, ofte etter hyppig bruk av dagligdagse produkter (tab 2 ).

Nikkel, kobolt, kromat og parfymestoffer er de hyppigst forekommende kontaktallerge- 
ner den vestlige befolkning møter $(7,11)$. Nikkelallergi er den vanligste form for kontaktallergi, og i EU ble salg av nikkelholdige produkter som vil være i kontakt med huden forbudt fra 1997. Man antar at dette tiltaket vil medføre at insidensen for nikkelallergi avtar (12). Flere studier viser at insidensen av kontaktallergi er høyere hos kvinner enn hos menn (7). Det er økt hyppighet av kontaktallergi innenfor yrker der man daglig utsettes for kontakt med allergifremkallende stoffer, det gjelder f.eks. frisører og mekanikere.

\section{Utredning av kontaktallergi}

Kontaktallergi kan utredes med epikutantester (lappetest, patchtest) $(6,8,9,12-14)$. Man har et antall testserier. Den mest brukte ved Rikshospitalet er standardserien (fra Chemotechnique Diagnostics), som inneholder 26 ulike stoffer, deriblant de vanligste allergenene. Vehikkelserien som brukes ved Rikshospitalet inneholder åtte ulike midler, bl.a. Brulidine. Denne serien settes sammen i avdelingen. Det finnes også testserier rettet mot spesielle grupper av stoffer eller utsatte yrkesgrupper. Ved andre mistenkte allergener er det mulig å bruke egne stoffer som fortynnes.

Epikutantestene utføres ved at stoffene legges i små skåler på et område med normal hud, oftest på rygg eller lår. Lappene fjernes vanligvis etter to dager, og avlesning skjer etter 2-7 dager. Reaksjonen graderes fra I til IV, der II er en sikker positiv reaksjon.

Ved mistanke om allergisk kontakteksem for medikamenter, kosmetikk eller annet som er produsert for å brukes på huden, kan man benytte seg av en såkalt brukertest. Denne utføres ved at pasienten smører mistenkt agens på et friskt hudområde på ca. $4 \times 4 \mathrm{~cm}$ to ganger daglig i opptil sju dager. Ved reaksjon under applikasjonen skal man avslutte tidligere. Positiv brukertest, dvs. eksematøse forandringer i testområdet, indikerer oftest at pasienten har kontaktallergi for påførte agens. Irritativ reaksjon kan imidlertid også gi positiv test, mens negativ test stort sett vil utelukke allergi. Ved en positiv brukertest er det anbefalt å gå videre med epikutantesting.

\section{Konklusjon}

Disse to kasuistikkene illustrerer hvor viktig en grundig anamnese kan være for å finne årsaken til akutt eksem og sår med manglende tilheling. Pasientene har lett for å glemme å nevne håndkjøpspreparater som de har brukt i egenbehandling.

\section{Teresa Løvold Berents}

tberents@rikshospitalet.no

Karianne Nodenes

Hudavdelingen

Rikshospitalet

0027 Oslo

Oppgitte interessekonflikter: Ingen

\section{Litteratur}

1. Tørisen HM, red. Felleskatalogen. Oslo: Fagbokforlaget, 2007: 209.

2. Lützow-Holm C, Rønnevig JR. Allergic contact dermatitis from dibrompropamidine cream. Contact Dermatitis 1988; 18: 100-1.
3. Lützow-Holm C. Allergic contact dermatitis from dibrompropamidine cream. Contact Dermatitis 1989; 20: 160

4. Tupker RA, Schuur J, Coenraads PJ. Irritancy of antiseptics tested by repeated open exposures on the human skin, evaluated by non-invasive methods. Contact Dermatitis 1997; 37: 213-7.

5. Saint-Mezard P, Rosieres A, Krasteva M et al. Allergic contact dermatitis. Eur J Dermatol 2004; 14: 284-95.

6. Braun-Falco O, Plewig G, Wolff HH et al. Dermatology. New York: Springer Verlag, 2000, 467-81.

7. Schäfer T, Böhler E, Ruhdorfer S et al. Epidemiology of contact allergy in adults. Allergy 2001; 56 $1192-6$

8. Kar-Seng L, Mark BYT, Anthony TJG et al. Contact sensitization in patients with chronic venous leg ulcers in Singapore. Contact Dermatitis 2007; 56: $94-8$

9. Giordano-Labadie F, Rancé F, Pellegrin F et al. Frequency of contact allergy in children with atopic dermatitis: results of a prospective study of 137 cases. Contact Dermatitis 1999; 40: $192-5$.

10. Dotterud LK, Smith-Sivertsen T. Allergic contact sensitization in the general adult population: a population-based study from Northern Norway. Contact Dermatitis 2007; 56: $10-5$.

11. Helsing P. NOLAR Årsrapport 2005/2006. Oslo: Norsk Dermatologisk Selskap, Kvalitetsutvalget, 2007

12. Jensen CS, Lisby S, Baadsgaard 0 et al. Decrease in nickel sensitization in a Danish schoolgirl population with ears pierced after implementation of a nickel-exposure regulation. Br J Dermatol 2002 146: 636-42.

13. Cronin E. Contact dermatitis. New York: Churchill Livingstone, 1983.

14. Hansen S, Kroon S. Epikutantesting og nikkelallergi. Tidsskr Nor Legeforen 2008; 128: 433-5.

Manuskriptet ble mottatt 2.11.2007og godkjent 12.6. 2008. Medisinsk redaktør Odd Terje Brustugun.

\section{Kommentar}

\section{Når behandlingen er problemet}

Artikkelen til Berents \& Nodenes illustrerer flere viktige dermatologiske poenger.

For det første: De vanligste årsaker til uventet dårlig respons på behandling av hudsykdom er gal diagnose eller feilslått terapivalg. Muligheten for kompliserende allergisk kontaktreaksjon overfor lokalt nyttede midler må imidlertid alltid has in mente, særlig når de kliniske funn trekker i denne retning.

For det andre: Så lenge pasienten holder seg til reseptbelagt lokalbehandling, vil legen ha god kontroll med aktuelle virkestoffer og tilsetningsstoffer. Det må imidlertid alltid tas høyde for at mange pasienter supplerer den foreskrevne behandlingen med reseptfrie legemidler, kosmetika eller naturpreparater.

Kontaktallergiske reaksjoner overfor håndkjøpspreparater er mindre vanlig enn kontaktallergi mot topikale midler generelt (1). Det stiller krav til legens årvåkenhet. Spør alltid om bruk av slike preparater samt om bruk av ikke-medisinske midler når den kliniske utvikling ikke er som forventet!

Kontaktallergi overfor dibrompropamidin (Brulidine) ses ikke ofte, men bruken av substansen er utbredt. De samme forhold gjør seg gjeldende for velkjente håndkjøpspreparater som krotamiton (Eurax) (2), bacitracin (Bacimycin) (3) og lidokain (4). Paradoksalt nok kan også håndkjøpspreparatet hydrokortison og andre lokale steroider føre til kontaktallergi, noe som er en virkelig utfordring for dermatologen (5).

Jeg vil også, som Berents \& Nodenes, slå et slag for «brukertest» som metode. Så lenge man ikke tester med åpenbare irritanter (f.eks. vaskemidler), er dette en bra og kanskje undervurdert måte å tilnærme seg fenomenet kontaktallergi på. Etter 16 år $\mathrm{i}$ faget hudsykdommer har jeg ennå ikke sett en henvisning som refererer til resultatet av «brukertest » - men den ville nok blitt godt mottatt! Hvorvidt en positiv «brukertest» skyldes kontaktallergi mot aktivt virkestoff eller mot andre tilsetninger i produktet, er noe som dermatologen kan finne ut av i ettertid ved hjelp av målrettet lappetesting.

\section{Dag Sollesnes Holsen}

dag.holsen@helse-bergen.no Hudavdelingen

Haukeland universitetssykehus

5021 Bergen

\section{Litteratur}

1. de Pàdua CA, Schnuch A, Nink K et al. Allergic contact dermatitis to topical drugs - epidemiological risk assessment. Pharmacoepidemiol Drug Saf 2008; 17: 813-21. doi: 10.1002/pds.1588.

2. Hara H, Masuda T, Yokoyama A et al. Allergic contact dermatitis due to crotamiton. Contact Dermatitis 2003; 49: 219

3. Schalock PC, Zug KA. Bacitracin. Cutis 2005; 76 : $105-7$.

4. Amado A, Sood A, Taylor JS. Contact allergy to lidocaine: a report of sixteen cases. Dermatitis 2007; 18: 215-20

5. Matura M, Goossens A. Contact allergy to corticosteroids. Allergy 2000; 55: 698-704.

Manuskriptet ble mottatt 2.1. 2009 og godkjent 9.1. 2009. Medisinsk redaktør Odd Terje Brustugun. 